\title{
Electrochemical study and characterization of tin coatings with and without glucose-based additive
}

\author{
Sghir Cherrouf ${ }^{1}$, Yassine Salhi ${ }^{1, *}$, Amina El Echhab ${ }^{1}$. Hassan El Grini ${ }^{1}$, Jihane Tellal ${ }^{1}$, Mohammed \\ Cherkaoui $^{1,2}$ and Brahim Lakhrissi ${ }^{3}$ \\ ${ }^{1}$ Laboratory of Materials, Electrochemistry and Environment, Ibn Tofail University, Faculty of Sciences, \\ Kénitra, Morocco \\ ${ }^{2}$ National Higher School of Chemistry, Ibn Tofail University, Po Box 133-14050, Kénitra, Morocco \\ ${ }^{3}$ Agroressources and Process Engineering Laboratory, Ibn Tofaïl University, Faculty of Sciences, Kénitra,
} Morocco

\begin{abstract}
The tin coating was elaborated electrolytically on an ordinary steel substrate in $\mathrm{SnSO}_{4}$ based electrolyte in acid medium with additive (bis-glycobenzimidazolone) at ambient temperature. The $\mathrm{pH}$ is maintained at $1.2 \pm 0.2$ Bis-glycobenzimidazolone influence on the electrochemical properties of the tin coating was investigated using stationary polarization, chronopotentiometry, and cyclic voltammetry techniques. These studies show an apparent decrease in cathodic peak current and a drop in potential. The deposition rate also decreases as the concentration of the additive increases. SEM (Scanning Electron Microscopy) observation and XRD (X-ray Diffraction) analysis showed that the coating consists of good surface quality of the deposit elaborated by the addition of an optimal concentration of bis-glycobenzimidazolone $\left(10^{-3} \mathrm{M}\right)$ in the electrolyte, which constitutes the continuation of a preliminary study.
\end{abstract}

Keywords: Tin coating; Bis-glycobenzimidazolone; electrolytically; Cathodic polarization; Chronopotentiometry; Cyclic voltammetry; deposition rate; SEM; XRD; optimal concentration.

\section{Introduction}

Though tin electrodeposition has been known since the mid-nineteenth century, the process is still exciting, and improvement is always crucial. There are many reasons to choose tin coatings: the good solderability properties ${ }^{1-5}$, the non-toxicity ${ }^{1,3,5}$, and the excellent corrosion resistance ${ }^{1-2,5}$. Therefore, tin coatings have a wide range of applications and are used in both the food industry and electronic industry 1,4-7. Furthermore, tin coating and its alloys are solicited to replace chromium and cadmium deposits ${ }^{3,8-10}$ because of their toxicity.

In acidic baths, tin layers are poriferous, less adherent, and rough with the spontaneous formation of thin filaments on the surface due to a high deposition overvoltage ${ }^{4,6,9,11-12}$. Initially, lead was often added in the electrodeposition electrolytes to decrease this overvoltage $^{13}$. However, the wastewater from baths containing lead presents real environmental problems. To remedy this problem, several authors have suggested the addition of organic compounds ${ }^{11,14-15}$ or surfactants 12,16-17, which can play the same role as lead. Some efforts have been made to develop appropriate additives and to discover their modes of

*Corresponding author: Yassine Salhi

Email address: y.salhi33@gmail.com

DOI: http://dx.doi.org/10.13171/mjc02110281589salhi intervention in the deposition kinetics and thus their impact on the morphological properties and structure. These compounds can change tin voltage reduction, decrease the hydrogen evolution and reduce the surface roughness as a result ${ }^{2,6-7,18}$.

The present work is the continuation of a previous study in which we have studied the effect of bisglycobenzimidazolone on tin coating electrochemical and morphological properties. An optimal concentration of the additive mentioned above helps improve the surface state, becoming more adherent and uniform. The reasons that lead to bisglycobenzemidazolone are: First, the additive helps improve tin electrodeposition by blocking active sites on the metal surface. Second, this additive is environmentally friendly. Third, the use of that additive helps decrease the current, which will save energy. In perspective, we will go deeper with more details in our coming work.

This study was carried out by stationary polarization, chronopotentiometry, and cyclic voltammetry techniques. At the same time, the surface state characterization of the elaborated deposit was determined by X-ray diffraction (XRD) and scanning electron microscopy (SEM).

Received July 10, 2021

Accepted August 5, 2021

Published October 28, 2021 


\section{Experimental work}

The electrolytes were prepared using analytical-grade chemicals. The $\mathrm{pH}$ is maintained at $1,2 \pm 0.2$ to meet industrial conditions, and the temperature was kept at $20 \pm 1^{\circ} \mathrm{C}$. Table 1 summarizes the baths compositions of this study. The additive is bisglycobenzimidazolone.

The so-called additive was synthesized by a method described by Lakhrissi and al ${ }^{19}$ as it was mentioned in a previous study ${ }^{20}$. A cell of $200 \mathrm{ml}$ was used. The substrates were iron plates $\left(1 \mathrm{~cm}^{2}\right)$ mechanically polished down to $1200 \mathrm{SiC}$ paper, degreased in ethanol, etched in dilute sulfuric acid, and rinsed with demineralized water before the experiment. Metal salt (SnSO4) was dissolved in distilled water first. Then sulfuric acid was poured into the solution under magnetic stirring. Additive preparation consists of dissolving bis-glycobenzemidazolone in distilled water for 5 min under magnetic stirring. After that, a given volume of additive will be poured into the beaker containing $\mathrm{SnSO}_{4}$, distilled water, and sulfuric acid, according to Table 1 . The deposit rate was estimated from the weight gain after immersion time (1/2-1h).

The electrochemical measurements were carried out using Potentiostat/Galvanostat/Voltalab PGZ 100 monitored by a personal computer in the laboratory. The morphology of coatings was examined with a FEI Quanta 200 scanning electron microscope at CNRST (Centre National de Recherche Scientifique et Technique - Rabat). In addition, XRD measurements were made on a PANalytical diffractometer type X'PERT3 POWDER with $\mathrm{Cu} \mathrm{K} \alpha 1$ radiation in CUAETTI (Centre Universitaire d'Analyse, d'Expertise de Transfert de Technologie et d'Incubation - Ibn Tofail University - Kénitra).

Table 1. Composition of studied baths.

\begin{tabular}{|c|c|c|c|}
\hline Electrolytes & $\mathrm{SnSO}_{4}(\mathrm{M})$ & $\mathrm{H}_{2} \mathrm{SO}_{4}(\mathrm{M})$ & Additive (M) \\
\hline 1 & 0.14 & 0.56 & 0 \\
\hline 2 & 0.14 & 0.56 & $10^{-5}$ \\
\hline 3 & 0.14 & 0.56 & $10^{-3}$ \\
\hline
\end{tabular}

\section{Results and discussion}

\subsection{Deposition rate}

The following formula determined the deposition rate $\mathrm{R}$ :

$$
\mathbf{V}(\boldsymbol{\mu m} / \mathbf{h})=\frac{\mathbf{m f}-\mathbf{m i}}{\text { e.s.t }}
$$

Many authors use this formula to determine the deposition rate without bibliographic evidence.

e: coating thickness $(\mu \mathrm{m}), \mathbf{t}$ : deposition time $(\mathrm{h})$ $\mathbf{m}_{\mathbf{f}}$ : final weight of the sample; $\mathbf{m}_{\mathbf{i}}$ : initial weight of the sample, $\mathbf{S}\left(\mathrm{cm}^{2}\right)$ : substrate surface $\left(1 \mathrm{~cm}^{2}\right)$.

For an electrodeposited coating, at $\mathrm{E}=-0.525 \mathrm{~V}$, the calculation shows that the deposition rate increases with the intensity of the applied current. Conversely, it also demonstrates that the deposition rate decreases in the presence of bis-glycobenzimidazolone for different applied currents.

Thus, the rate passes from $32,8 \mu \mathrm{m} / \mathrm{h}$ to $7 \mu \mathrm{m} / \mathrm{h}$ at $-15 \mathrm{~mA} / \mathrm{cm}^{2}$ with additive. Furthermore, the mechanism of tin deposition is controlled by diffusion, which would explain the decrease in deposition rate ${ }^{20}$. We noticed that the best surface state was obtained for a current density equal to $15 \mathrm{~mA} . \mathrm{cm}^{-2}$ at of $10^{-3}$ mole. $\mathrm{L}^{-1}$ concentration of bisglycobenzimidazolone. The optimal additive concentration is $10^{-3}$ mole. $\mathrm{L}^{-1}$.

\subsection{Electrochemical investigations \\ 3.2.1. Polarization curves}

The cathodic stationary current-voltage related to the baths 1, 2 and 3 increases more or less rapidly with the potential from $-475 \mathrm{mV}$ (Figure 1). We note that the current is lower in the presence of bisglycobenzimidazolone (Figure 1, curve 2, and curve 3 ). This current decreases as the concentration of bis-glycobenzimidazolone increases, confirming the additive's influence on the deposition rate. According to Figure 1, we notice that the intensity of the current decreases after remarkably adding the additive, especially at the concentration of $10^{-3} \mathrm{M}$, which confirms the influence of the additive on deposition speed. 


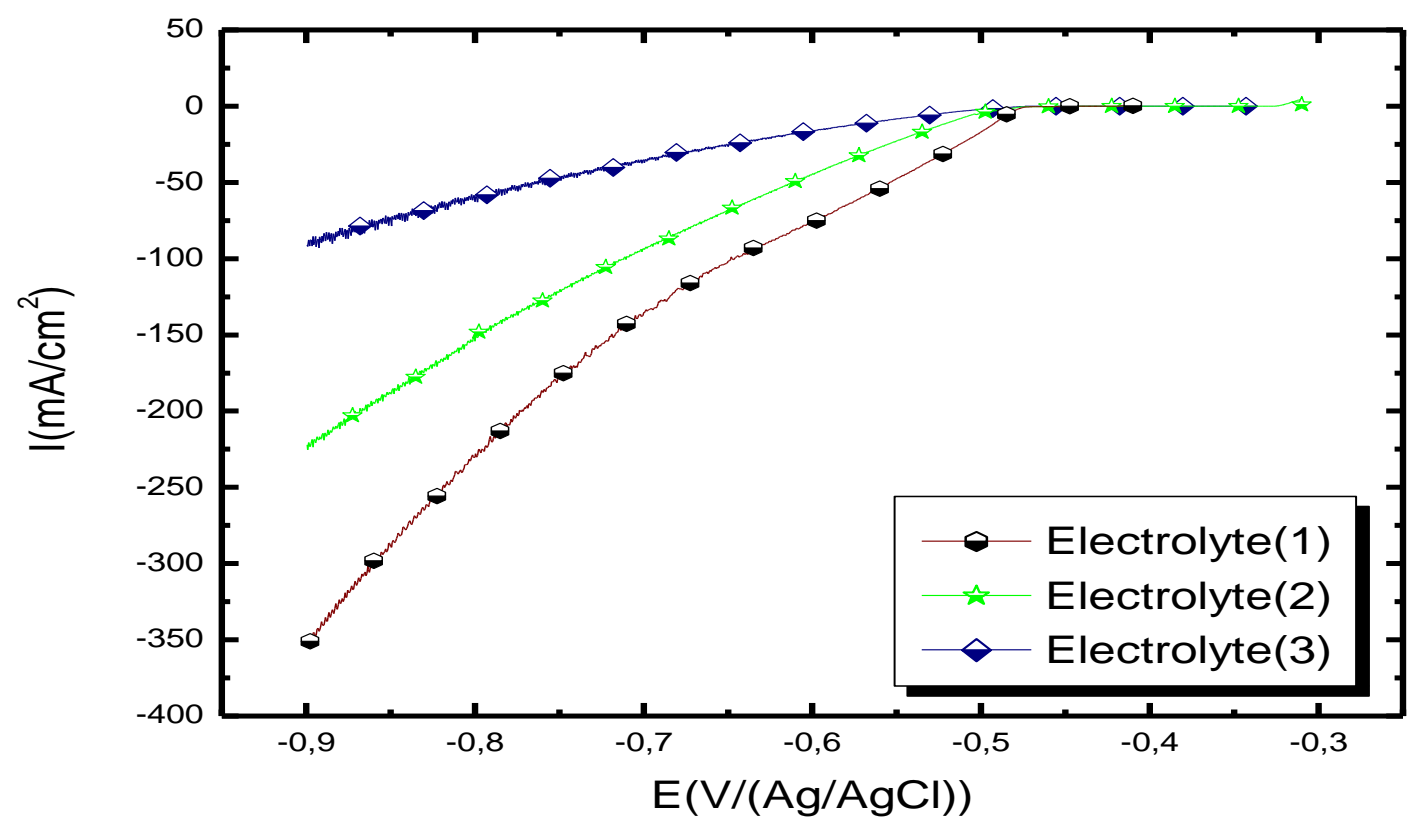

Figure 1. $I=f(E)$ curves with stirring, scan rate $=1 \mathrm{mV} / \mathrm{S}$ plotted respectively in baths: (1), (2) and (3).

\subsection{2. chronopotentiometry}

The transitory curves $E=f(t)$ plot for a current density of $-15 \mathrm{~mA} / \mathrm{cm}^{2}$ in the electrolyte (1), (2), and (3) (Figure 2) show a stabilization of potential at -476 $\mathrm{mV}$ for electrolyte (1) and - $490 \mathrm{mV}$ for electrolyte (2) ${ }^{20}$ while it reaches - $525 \mathrm{mV}$ in the case of electrolyte (3) at an optimal concentration of bisglycobenzimidazolone.
The transitory curves $E=f(t)$ plot for a current density of $-15 \mathrm{~mA} / \mathrm{cm}^{2}$ in the electrolyte (1), (2), and (3) (Figure 2) show a drop in potential that reaches $-525 \mathrm{mV}$ after the addition of bisglycobenzimidazolone at an optimal concentration of $10^{-3} \mathrm{M}$. The partial blockage of the surface could explain this by its adsorption.

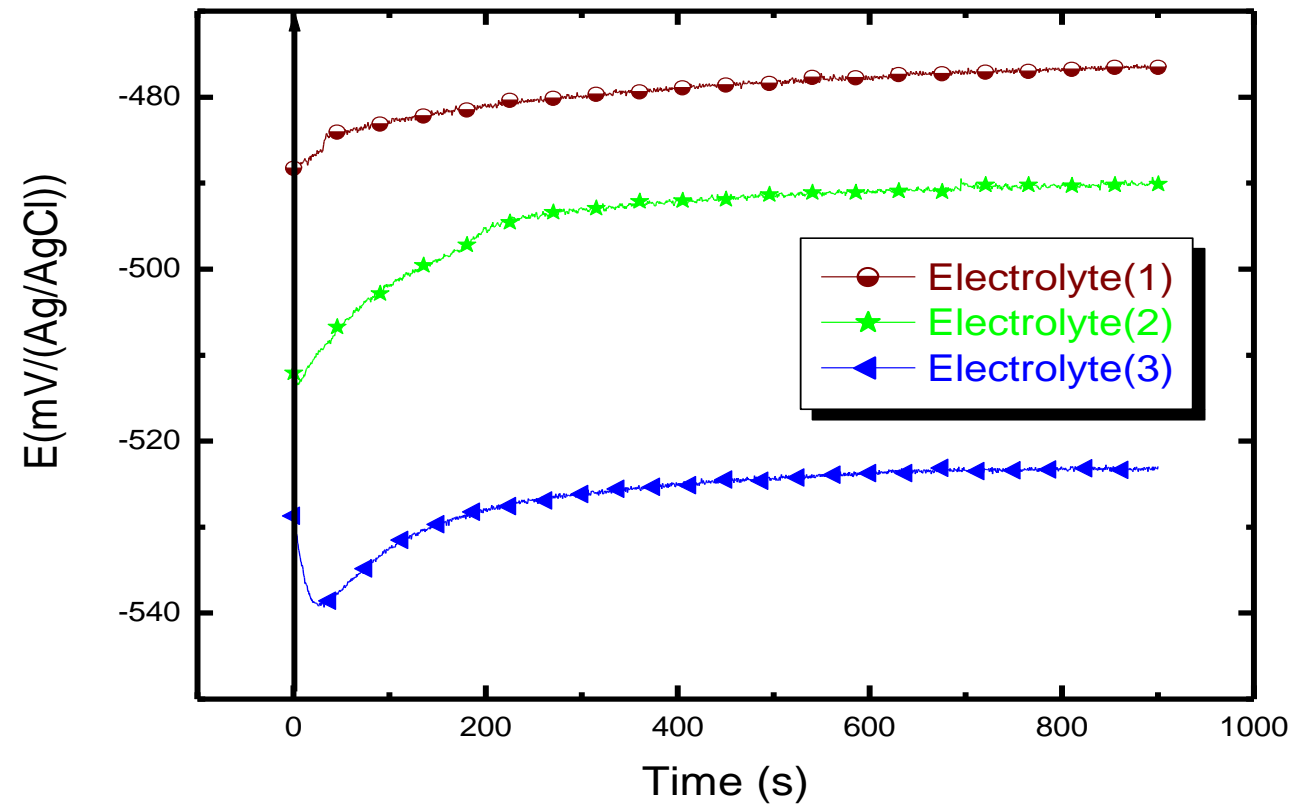

Figure 2. Chronopotentiometry curves for a current density of $-15 \mathrm{~mA} / \mathrm{cm}^{2}$ with stirring in baths: (1), (2) and (3).

\subsubsection{Cyclic voltammetry}

The cyclic voltammograms recorded at a scan rate of $10 \mathrm{mV} \cdot \mathrm{min}^{-1}$ in the electrolytes 1 and 3 are shown in Figure 3. In both cases, a cathodic peak (A) was observed at $-525 \mathrm{mV}$. During the reverse scan, the current was higher for the electrolyte (1) without additive than the direct scan, which confirms that a heterogeneous deposit has been formed ${ }^{21}$. In electrolyte (3), we note that the current obtained during the reverse scan is less critical than the direct scan. This confirms a compact and uniform deposit. In the anodic domain, in both electrolytes, an oxidation peak (B) was observed at $-325 \pm 10 \mathrm{mV}$. 
A decrease in the current density was observed from $525 \mathrm{mV}$ in the bath with and without bisglycobenzimidazolone related to the reduction of tin:

$\mathrm{Sn}^{\mathrm{II}}+2 \mathrm{e}^{-} \rightarrow \mathrm{Sn}$

A more detailed mechanism is proposed in the literature with the formation of hydrated stannic complexes $^{22}$ :

$3 \mathrm{Sn}^{2+}+4 \mathrm{H}_{2} \mathrm{O} \rightarrow\left(\mathrm{Sn}^{2+}\right)_{3}\left(\mathrm{H}_{2} \mathrm{O}\right)_{4}$

$$
\begin{aligned}
& \mathrm{Sn}^{4+}+2 \mathrm{H}_{2} \mathrm{O} \rightarrow \mathrm{Sn}^{4+}\left(\mathrm{H}_{2} \mathrm{O}\right)_{2} \\
& 2\left(\mathrm{Sn}^{2+}\right)_{3}\left(\mathrm{H}_{2} \mathrm{O}\right)_{4}+12 \mathrm{e}^{-} \rightarrow \mathrm{Sn}_{6} \mathrm{O}_{4}(\mathrm{OH})_{4}+6 \mathrm{H}_{2} \\
& \mathrm{Sn}^{4+}\left(\mathrm{H}_{2} \mathrm{O}\right)_{2}+4 \mathrm{e}^{-} \rightarrow \mathrm{SnO}_{2}+2 \mathrm{H}_{2}
\end{aligned}
$$

This increase is followed by a cathodic plateau due to diffusion of tin, and finally, the hydrogen evolution: $2 \mathrm{H}^{+}(\mathbf{a q})+2 \mathrm{e}^{-} \rightarrow \mathrm{H}_{2}(\mathrm{~g})$

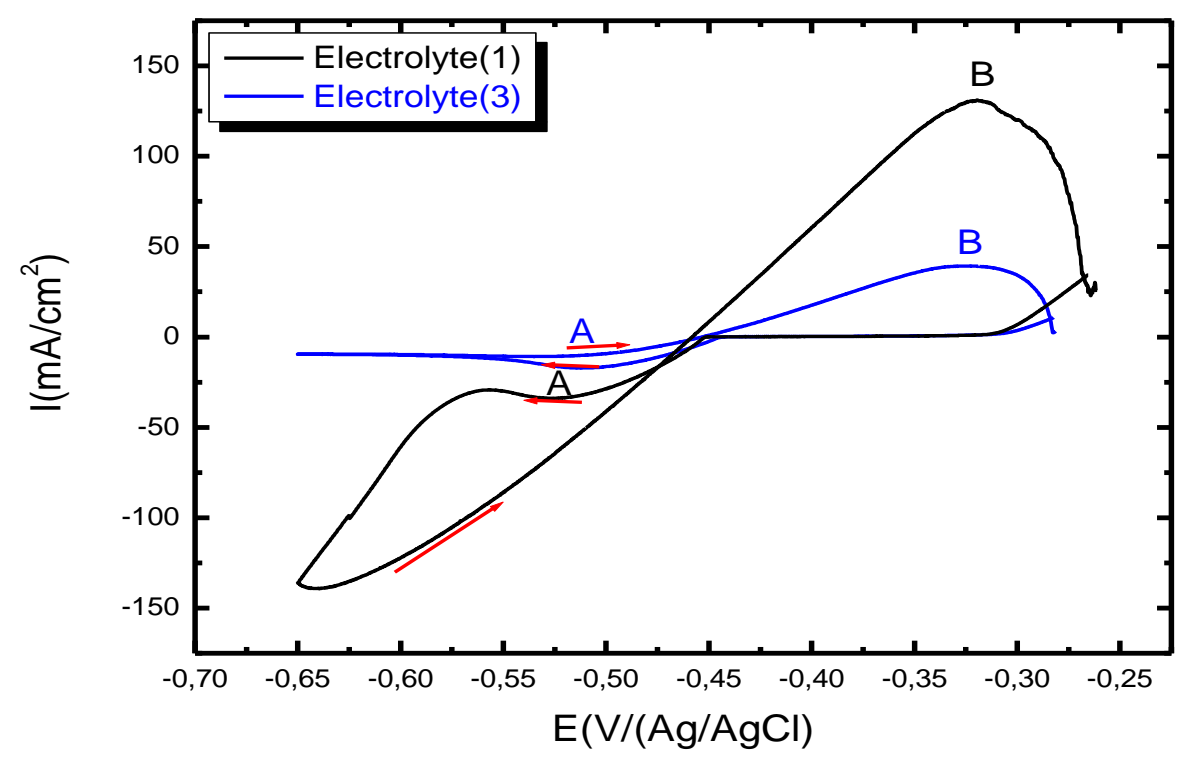

Figure 3. Cyclic voltammograms of tin electrodeposition in electrolyte with and without bisglycobenzimidazolone at a scan rate of $10 \mathrm{mV} \mathrm{S}^{-1}$.

As shown in Table 2, in the absence of the additive (electrolyte 1), the efficiency estimated by anodic and cathodic charges $\left(\mathrm{Q}_{\mathrm{a}} / \mathrm{Q}_{\mathrm{c}}\right)$ ratio was significantly less than the unity. This could be explained by the important reduction of $\mathrm{H}^{+}$and the incomplete anodic dissolution of tin deposit. The deposit has been detached and fallen in the bottom of the electrochemical cell during oxidation. However, this ratio increases significantly in the bath with additive (electrolyte 3). Indeed, it is clear that bisglycobenzimidazolone decreases hydrogen evolution ${ }^{23,24}$.

Table 2. Anodic and cathodic charges were calculated from tin deposit dissolution cyclic voltammograms (data extracted from Figure 3).

\begin{tabular}{|c|c|c|c|}
\hline Electrolyte & Qa $\left(\mathbf{m C ~} \mathbf{c m}^{-\mathbf{2}}\right)$ & $\mathbf{Q c}\left(\mathbf{m C ~} \mathbf{c m}^{-\mathbf{2}}\right)$ & Qa/Qc \\
\hline Electrolyte (1) & 1546,85 & 2521,16 & 0,614 \\
\hline Electrolyte (3) & 402,40 & 408,00 & 0,986 \\
\hline
\end{tabular}

\section{Surface morphology and crystalline orientation of electrodeposited tin}

\subsection{Surface morphology of electrodeposited tin} As shown in Figure 4, the tin deposit obtained in the basic bath containing no additive is very inhomogeneous, irregular, dendritic, and has large black spots.
We also note that the surface is not covered; some of the coatings are easily removed. In the presence of bis-glucobenzimidazolone, the surface state of the coating produced was improved mainly. The deposit is more uniform and more adhering ${ }^{23}$; it covers almost the entire surface.

The best surface state (Figure 5) was obtained at $10^{-3}$ mole. $\mathrm{L}^{-1}$ additive concentration is the optimal one. 


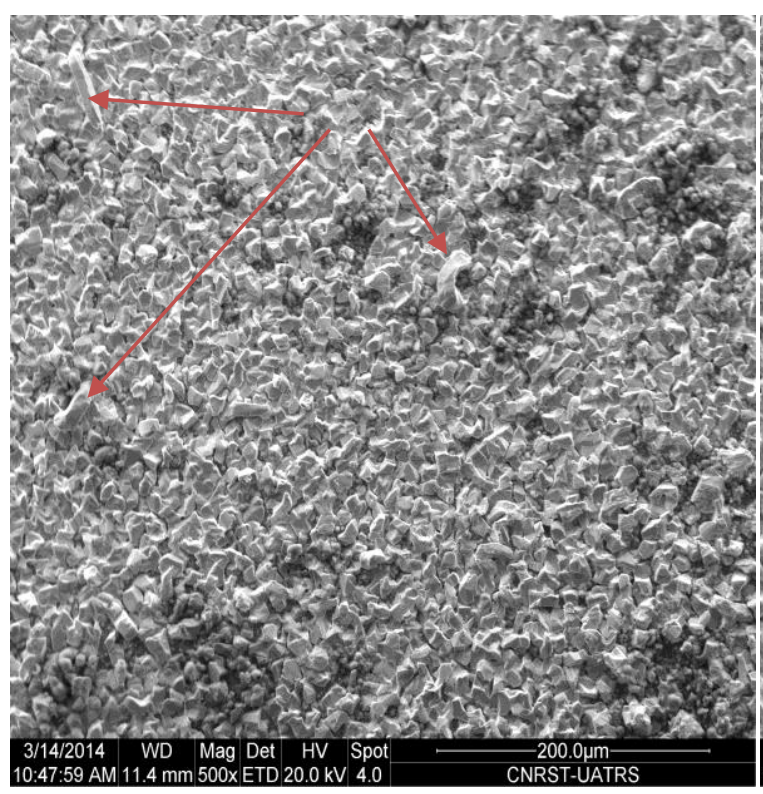

Figure 4. SEM images of Sn coating obtained at $\mathrm{I}=-15 \mathrm{~mA} / \mathrm{cm}^{2}$ from electrolyte (1)

\subsection{Crystalline orientation of electrodeposited tin} The X-ray patterns of Sn coatings performed at -15 $\mathrm{mA} / \mathrm{cm}^{2}$ in electrolytes 1 and 3 compared with JCPDS file of tin $\left(\mathrm{N}^{\circ}\right.$. 4-673) Figure $7^{25}$ are shown in Figure 6 . They all exhibit a tetragonal structure. The coating deposited from electrolyte (3) (with additive) presents the intensity of the orientation (200) slightly more significant than the one deposited from electrolyte (1) (without additive). In contrast, the

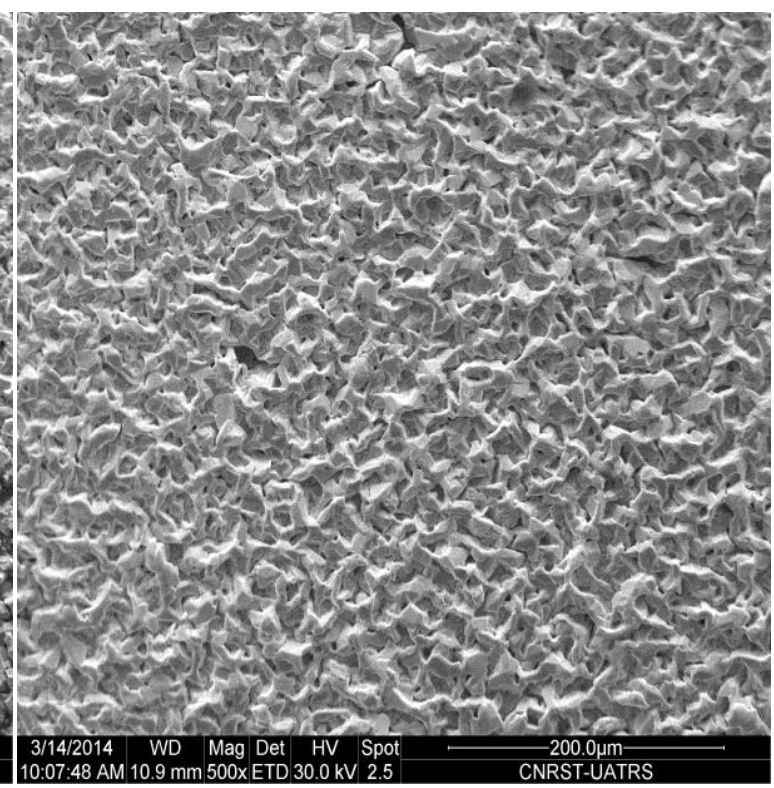

Figure 5. SEM images of Sn coating obtained at $\mathrm{I}=-15 \mathrm{~mA} / \mathrm{cm}^{2}$ from electrolyte (3)

intensity of the orientation (101) of the coating deposited from electrolyte (3) is significantly higher than the one deposited from electrolyte (1) ${ }^{23}$. In a previous study conducted in the bisglycobenzimidazolone, a robust preferential orientation in the direction (112) was observed ${ }^{2}$. This change in the preferential direction of tin deposit growth in the presence of the additive could also explain the improvement of the coating quality.

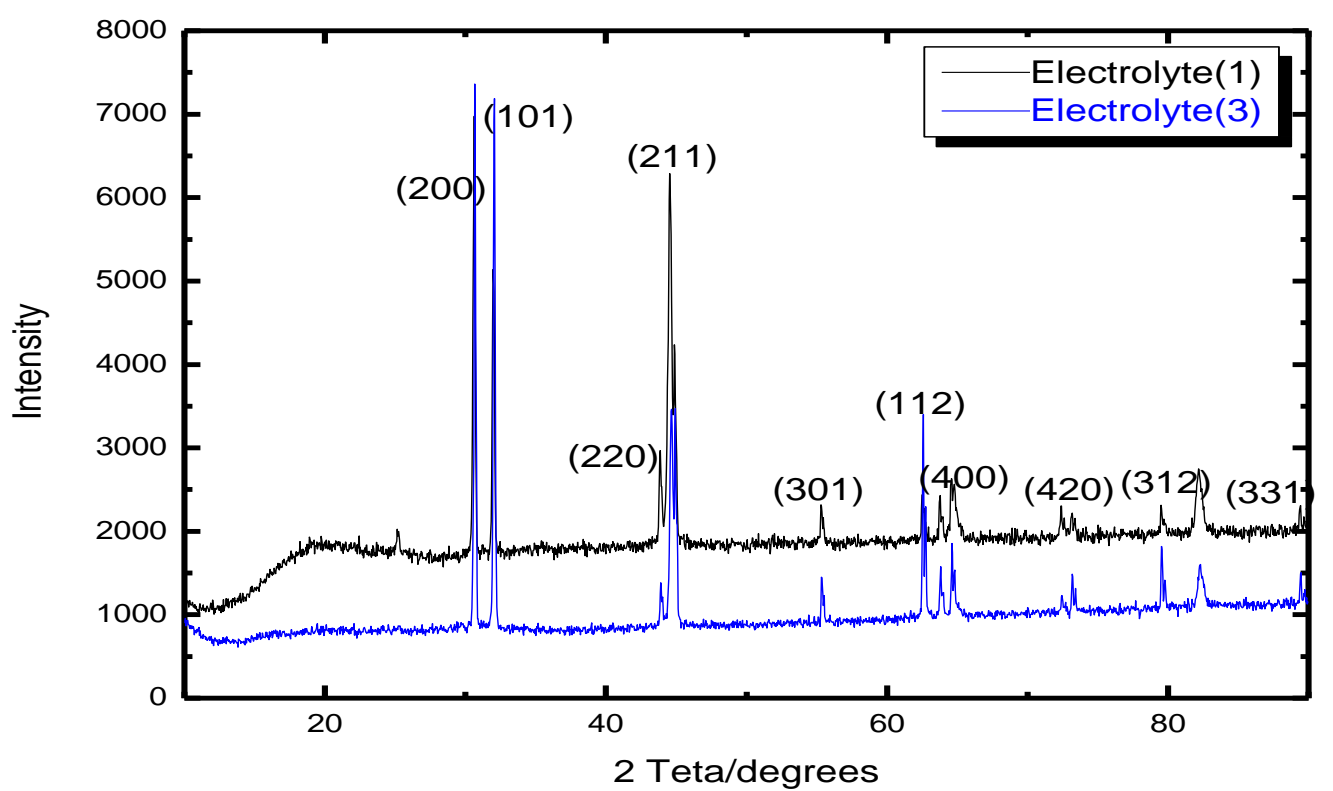

Figure 6. X-ray diffraction patterns of coatings deposited from electrolytes (1) and (3). 


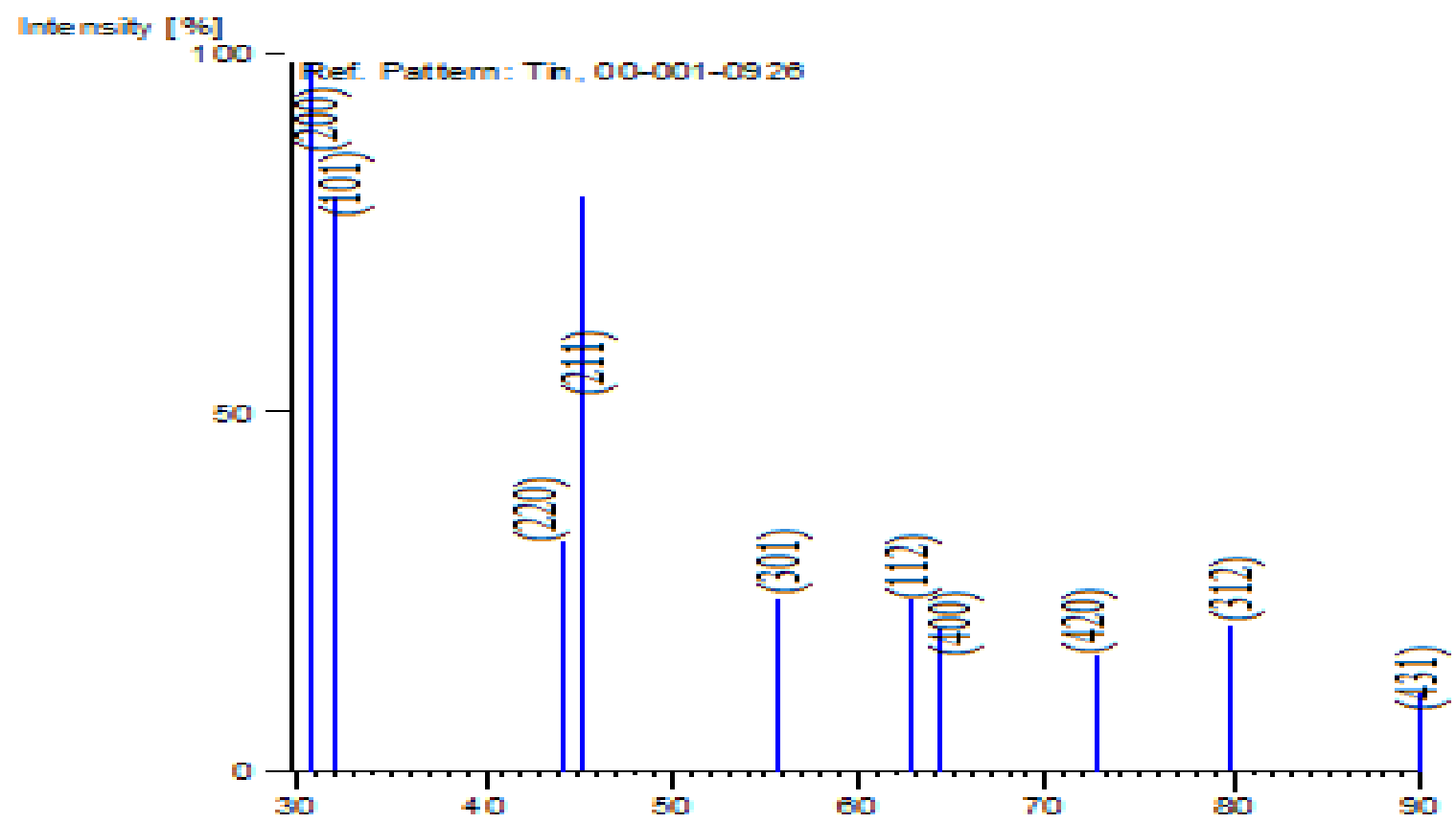

Figure 7. Reference pattern of tin (JCPDS file 4-673).

\section{Conclusion}

An optimal concentration of bisglycobenzimidazolone $\left(10^{-3} \mathrm{M}\right)$ was beneficial to help improve the surface state of tin coating. Furthermore, the anodic and cathodic charges $\left(\mathrm{Q}_{\mathrm{a}} / \mathrm{Q}_{\mathrm{c}}\right)$ ratio increases significantly in the bath with additive (electrolyte 3). It is evident that bisglycobenzimidazolone decreases hydrogen evolution which gives more adherent and uniform coatings. We concluded that the concentration of the additive is also a critical factor in getting more uniform and brilliant coatings at a current density of $-15 \mathrm{~mA} / \mathrm{cm}^{2}$.

\section{References}

1- Y. Salhi, S. Cherrouf, J. Tellal, M. Cherkaoui, Electrodeposition of $\mathrm{Cu}-\mathrm{Zn}-\mathrm{Sn}$ coating in citrate medium, Mediterr. J. Chem., 2020, 9(6), 456-467.

2- M. Charrouf, S. Bakkali, M. Cherkaoui, M. EL Amrani, Influence of decyl glucoside on the electrodeposition of tin J. Serbian. Chem., 2006, 71, 659-666. ,

3- V. W. Zhang, J. Guebey, M. Toben,

K. Weitershaus, Luzern/Schweiz., 2011, 520-528.

4- E. Chason, N. Jadhav, F. Pei, E. Buchovecky, A. Bower, Growth of whiskers from Sn surfaces: Driving forces and growth mechanisms, Progress in Surf. Sci., 2013, 88, 103-131.

5- K. Chat-Wilk, E. Rudnik, G. Włoch, Importance of anions in the electrodeposition of nickel from gluconate solutions, Ionics, 2021, 27, 4393-4408.

6- S. Bakkali, T. Jazouli, M. Cherkaoui, M. Ebn Touhami, N. EL Hajjaji, E. Chassaing, Influence of M12 organic additive on the electrodeposition of tin from an acid sulfate solution, Plat. and Surf. Finish., 2003 ,90, 1, 46-49.

7- K. N. Strafford, A. Reed, Coatings reduce the fouling of microfiltration membranes, Coat. \& Surf. Treat. for Corr. and Wear Resist., 1984, 74.

8- G. S. Tzeng, S. H. Lin, Y. Y. Wang, C. C. Wan, Effects of additives on the electrodeposition of tin from an acidic Sn (II) bath, J. Electroanal. Chem., 1996, 26, 419-423.

9- E. Guaus, J. Torrent-Burgues, Tin-zinc electrodeposition from sulphate-gluconate baths, Journal of Electroanalytical Chemistry, 2003, 549, 25-36.

10-A. Aragon, M. G. Figueroa, R. E. Gana, J. H. Zagal, Effect of a polyethoxylate surfactant on the electrodeposition of tin, J. Appl. Electrochem., 1992, 22, 558 -562.

11-G. S. Thzeng, Plat. and Surf. Finish., 1995 ,82,67-72.

12-S. Meibuhr, E. Yeager, A. Kozawa, F. Hovorka, The electrochemistry of tin: I. Effects of nonionic addition agents on electrodeposition from stannous sulfate solutions, J. Electrochem. Soc., 1963, 110, 190-202.

13-C. L. Rinne, J. J. Hren, P. S. Fedkiw, Electrodeposition of tin needle-like structures, J. Electrochem. Soc. 2002,149, C150-158.

14-E. Rudnik, G. Chowaniec, Effect of organic additives on electrodeposition of tin from acid sulfate solution, Metallurgy and Foundry Engineering, 2018, 44(1), 41-52.

15-I. Yawata, S. Company, UK Patent, 1966, 16-21.

16-Zavarine, I. Khaselev, O. Y. Zhang, J. Electrochem. Soc. 2003, 150,202-207. 
17-P. A. Kohl, The high-speed electrodeposition of $\mathrm{Sn} / \mathrm{Pb}$ alloys, J. Electrochem. Soc., 1982, 129, 1196-1201.

18-C.T.J. Low, F.C. Walsh, The influence of a perfluorinated cationic surfactant on the electrodeposition of tin from a methanesulfonic acid bath, J. Electroanal. Chem, 2008, 615, 91-102.

19-B. Lakhrissi, B. El Azzaoui, A. Nabil, E. M. Essassi, M. Massoui, G. Goethals, P. Villa, C. Solans, N. Azemar, F. Comelles, M. J. GarciaCelma, N. Sadurni, P. G. Jorn, Com. Esp. Deterg., 2000, 30, 233-243.

20-S. Cherrouf, Y. Salhi, A. Benabida, H. Elgrini, M. Cherkaoui, L. Lakhrissi, B.Lakhrissi, Elaboration of tin deposits in the presence of Bisglucobenzimidazolone, Moroccan Journal of Chemistry, 2014, 2(3), 175-180.

21-L. H. Mendoza-Huizar, J. Robles, M. PalomarPardavé, Nucleation and growth of cobalt onto different substrates: Part II. The upd-opd transition onto a gold electrode, Journal of Electroanalytical Chemistry, 2003, 545, 39-45. 22-M. A.Shikun, O. N. Vrublevskaya, T. N. Vorobyova, Functions of 2-butyne-1, 4-diol in the process of tin-silver alloy electrodeposition from the acidic sulfate solution, Surfaces and Interfaces, 2021, 24, 101059.

23-S. Cherrouf, Y. Salhi, M. Cherkaoui, B. Lakhrissi, N. Lakhrissi, Study of the influence of a bis-glycobenzimidazolone on the reduction of stannous ions, J. Mater. Environ., 2016, 7(7), 2595-2602.

24-S. Bakkali, R. Touir, M. Cherkaoui, M. Ebn Touhami, Influence of S-dodecylmercapto benzimidazole as an organic additive on electrodeposition of tin, Surface \& Coatings Technology, 2014, S0257(14), 8972-8991.

25-Joint Committee on Powder Diffraction Standards (JCPDS) International Center for Diffraction File PDF-2 Database 2000, 1-49. 